\title{
Surface-exposed Epitopes on the Major Outer-membrane Protein of Chlamydia trachomatis Defined with Peptide Antisera
}

\author{
By J. W. CONLAN,* S. FERRIS, I. N. CLARKE AND M. E. WARD \\ Department of Microbiology, University of Southampton Medical School, Southampton General \\ Hospital, Tremona Road, Southampton SO9 $4 X Y$, UK
}

(Received 16 June 1989; revised 26 July 1989; accepted 31 July 1989)

\begin{abstract}
The surface exposure of computer-predicted, linear B-cell epitopes on the major outermembrane protein (MOMP) of Chlamydia trachomatis serovar B was assessed using antibodies raised against synthetic peptides in conjunction with immunogold transmission electron microscopy. Several of the chosen peptides elicited antibodies which reacted with both denatured and native MOMP. The majority of the exposed epitopes were found within the variable segments of MOMP. For each of the epitopes identified, the extent of their surface accesssibility varied both among individual organisms and different developmental forms. Evidence for two distinct subspecies-specific epitopes within VS4 is presented.
\end{abstract}

\section{INTRODUCTION}

The obligate intracellular bacterium Chlamydia trachomatis is a major cause of ocular (trachoma) and genital tract infections, with blindness and infertility, respectively, the most significant complications. Immunization of man, and other primates, with crude preparations of whole chlamydiae only produced short-term protection, which was serovar-specific; however, vaccination also generates long-lasting, genus-specific reactions which enhance the severity of the disease upon re-infection with heterologous serovars of $C$. trachomatis (reviewed in Schachter \& Dawson, 1978). These findings have focussed attention onto the use of defined chlamydial antigens as vaccines, most notably the major outer-membrane protein (MOMP). MOMP is the major structural protein exposed at the surface of the infectious elementary body (EB). A relatively cysteine-rich protein, MOMP functions as an outer-membrane porin which, under redox control, regulates nutrient ingress (Bavoil et al., 1984; Hatch et al., 1984) and thereby the differentiation of EB to reticulate bodies (RB). Polyclonal antibodies directed against MOMP block the intracellular differentiation of endocytosed chlamydiae (Caldwell \& Perry, 1982). Moreover, MOMP probably plays a part in the interaction of chlamydiae with the host cell, as antibodies directed against the immunoaccessible serovar- and subspecies-specific epitopes on MOMP neutralized chlamydial infectivity both in vitro and in vivo (Lucero \& Kuo, 1985; Zhang et al., 1987). The surface exposure of epitopes on MOMP in situ on the native organism appears to be the main determinant for neutralization by antibody (Zhang et al., 1987); antibodies to the less well exposed species- and genus-specific epitopes are not neutralizing.

Partial or complete inferred amino acid sequences of the MOMPs for all serovars of $C$. trachomatis (Baehr et al., 1988; Pickett et al., 1987; Stephens et al., 1987; Yuan et al., 1989) and for the C. psittaci ovine abortion agent (Pickett et al., 1988) have recently been described. The comparative sequences revealed four variable segments (VS1-VS4) interspersed amongst

\footnotetext{
Abbreviations: EB, elementary body; IB, intermediate body; KLH, keyhole limpet haemocyanin; micro IF, microimmunofluorescence; MOMP, major outer-membrane protein; RB, reticulate bodies; TEM, transmission electron microscopy; TFA, trifluoroacetic acid.
} 
constant regions which must have been conserved through chlamydial evolution (Stephens et al., 1987). Epitopic domains within the variable segments of MOMP have been mapped to linear sequences of 9 to 11 amino acids using murine monoclonal antibodies and either free-solution peptides (Stephens et al., 1988) or expressing $\lambda$ gt 11 recombinants (Baehr et al., 1988). Epitope localization and the structural requirements for antibody binding have been further defined to single amino acid resolution by solid-phase peptide mapping (Conlan et al., 1988, 1989). Typespecific epitopes have been demonstrated in both VS1 for serovar A (Baehr et al., 1988) and VS2 for serovars B, C, L1 and L2 (Baehr et al., 1988; Conlan et al., 1988; Stephens et al., 1988) whilst subspecies- and species-specific epitopes were consistently found in VS4 (Baehr et al., 1988; Conlan et al., 1988; Stephens et al., 1988). Together, VS1, VS2 and VS4 contain the main known immunodominant and surface-exposed epitopes, antibodies to which are capable of neutralizing chlamydial infection (Lucero \& Kuo, 1985; Zhang et al., 1987). Clearly, a key question for vaccine development is whether antibodies raised against peptides from VS1, VS2, VS4 or other potential epitopic regions are capable of reacting with the surface of native chlamydiae. Accordingly we have synthesized peptide homologues of C. trachomatis serovar B MOMP of 1213 amino acids in length, selected on the basis of their potential as B-cell epitopes using the computer program of Krchnak et al. (1987). Antisera prepared against these peptides were then used to determine the surface exposure of the corresponding regions on intact, viable chlamydiae using immuno-gold transmission electron microscopy (TEM).

\section{METHODS}

Organisms. C. trachomatis serovar B (strain B/Jali 20/OT) was grown and purified as previously described (Salari \& Ward, 1981). Organisms were stored in cryopreservative at $-80^{\circ} \mathrm{C}$ to preserve their viability and surface structure.

Prediction of B-cell epitopes. The inferred amino acid sequence for serovar B/Jali 20/OT MOMP was kindly made available by Dr M. Pickett (Department of Microbiology, Southampton University) whilst the sequence for another serovar B strain of $C$. trachomatis (B/TW5/OT) has been published (Stephens et al., 1987). Computer prediction of potential B cell epitopes in these sequences was performed using a published program (Krchnak et al., 1987) kindly provided on disc by Dr V. Krchnak (Leciva Pharmaceuticals, Prague, Czechoslovakia). This program uses the algorithms of Hopp \& Woods (1981) and Chou \& Fasman (1978) to predict hydrophilicity, probability of $\beta$-turn occurrence and preferred conformation for all overlapping tetrapeptides of a given sequence.

Peptide synthesis. Nine peptides, covering approximately $25 \%$ of the total MOMP sequence, were selected for synthesis. An additional, non-natural, cysteine residue was attached at the C-terminus of each peptide to facilitate coupling to carrier protein. Those peptides which did not contain a natural aromatic amino acid were synthesized with an N-terminal tyrosine to aid in UV detection during chromatography. Peptides were synthesized by conventional chemistry on RapidAmide resin using a RAMPs (DuPont) manual synthesizer in accordance with the manufacturer's instructions. The synthesis utilized pentafluorophenyl esters of fluorenylmethyloxycarbonyl (Fmoc) L-amino acids (Millipore) except for serine and threonine, where oxobenzotriazine esters were used, and arginine, which was coupled as the symmetric anhydride. Amino acid side-chain protecting groups were: $t$-butyl for cysteine, aspartic acid, glutamic acid, serine, threonine and tyrosine; t-butyloxycarbonyl for lysine and 4-methoxy-2,3,6-trimethylphenylsulphonyl for arginine. Coupling efficiency was monitored by assay with ninhydrin (Kaiser et al., 1970) or isatin (Kaiser et al., 1980) as appropriate. When necessary, amino acid couplings were repeated using different chemistries to ensure $>99 \%$ coupling efficiency. Following addition of the final residue, the $\mathrm{N}$-terminus of each peptide was acetylated with acetic anhydride in the presence of diisopropylethylamine. Peptides were cleaved from the resin by trifluoroacetic acid (TFA; $95 \%, \mathrm{v} / \mathrm{v})$ with ethandithiol $(0.5 \%, \mathrm{v} / \mathrm{v})$ and phenol $(4.5 \%, \mathrm{v} / \mathrm{v})$ present as scavengers. Cleaved peptides were precipitated four times with diethyl ether, twice with ethyl acetate/diethyl ether $(1.5: 1)$ and once with ether/water $(25: 1)$. Residual ether was removed under a stream of nitrogen gas and the precipitated peptides were lyophilized.

The purity of the peptides was initially assessed by analytical high-performance liquid chromatography (HPLC) on a Zorbax C8 (DuPont) reverse-phase column $(4.6 \times 250 \mathrm{~mm})$. Peptides were eluted with a linear $(10-60 \%)$ gradient of water/acetonitrile containing $0.1 \%$ TFA, generated over $30 \mathrm{~min}$ with a flow rate of $1 \mathrm{ml} \mathrm{min}^{-1}$. Purity of the peptides was confirmed by amino acid analysis using the Aminochrome system (Ciba Corning, UK).

Conjugation of peptides to carrier protein. Immediately prior to conjugation, the cysteine residues were deprotected and reduced to the thiol form with mercaptoethanol in accordance with the manufacturer's instructions. After reduction, the presence of free cysteine thiol groups was determined by reaction with 5,5'dithio-bis(2-nitrobenzoic acid) according to the method of Ellman (1959). Peptide (4 mg) was conjugated to an 
equal amount of the carrier protein keyhole limpet haemocyanin (KLH) using the method of Green et al. (1982). Conjugates were stored frozen at $-20^{\circ} \mathrm{C}$ prior to use.

Antisera. Antisera against the peptides were produced by immunizing male half-lop rabbits with KLH-peptide conjugates. A preliminary blood sample was first taken, then each rabbit was injected (day 1) with $200 \mu \mathrm{g}$ of conjugate in complete Freund's adjuvant (Sigma) distributed between two intramuscular and two dorsal subcutaneous sites. The animals were boosted with the same dose in incomplete Freund's adjuvant on days 14, 27, 55 and 66. Antisera were obtained on days 34 (first test serum) and 77 (second test serum). Antiserum against $C$. trachomatis B/Jali 20/OT was obtained by immunization with $100 \mu \mathrm{g}$ (protein) purified EB in incomplete Freund's adjuvant on days 1,14, 23 and 43; antiserum was collected on day 56 .

Elisa for antibody. Antisera were titrated by an indirect ELISA in 96-well PVC microtitre trays (high activated, Flow Laboratories) using the method of Robertson et al. (1987). For the detection of antibodies against chlamydiae, the wells were coated overnight at room temperature with whole EB $\left(5 \mu \mathrm{g}\right.$ protein $\mathrm{ml}^{-1}, 100 \mu \mathrm{l}$ per well) in $0.05 \mathrm{M}$-carbonate buffer $\mathrm{pH} 9.6$, containing $0.01 \%(\mathrm{w} / \mathrm{v})$ sodium azide. For the detection of anti-peptide antibodies, peptides were dissolved in $50 \%(\mathrm{v} / \mathrm{v})$ acetic acid then immediately diluted to $1 \mu \mathrm{g} \mathrm{ml}^{-1}(100 \mu \mathrm{l}$ per well) in carbonate buffer. The peptides were dried onto the plates by overnight incubation at $37^{\circ} \mathrm{C}$ in uncovered trays.

Immunoblotting. Chlamydial EB [strain B/Jali 20/OT, $1 \mathrm{mg}\left(\mathrm{ml}\right.$ protein) ${ }^{-1}$ ] were disrupted by boiling for $5 \mathrm{~min}$ in $0.0625 \mathrm{M}$-Tris/ $\mathrm{HCl} \mathrm{pH} 6.8$ containing $2 \%(\mathrm{w} / \mathrm{v}) \mathrm{SDS}, 10 \%(\mathrm{v} / \mathrm{v})$ glycerol, $5 \%(\mathrm{v} / \mathrm{v})$ mercaptoethanol and $0.01 \%$ $(\mathrm{w} / \mathrm{v})$ bromophenol blue. Whole-cell lysates were run on SDS-PAGE $(12 \%, w / v$, separating gel) using the buffer system of Laemmli (1970). After electrophoresis, gels were electroblotted onto nitrocellulose paper at $100 \mathrm{~mA}$ for $2 \mathrm{~h}$ using a semi-dry blotter (Ancos, Denmark) according to the method of Khyse-Andersen (1984). The nitrocellulose sheets were then blocked for $1 \mathrm{~h}$ at room temperature in Tris-buffered saline $\left(2.42 \mathrm{~g} \mathrm{Tris}^{-1}, 26.24 \mathrm{~g}\right.$ $\left.\mathrm{NaCl} 1^{-1} ; \mathrm{pH} 7.5\right)$ containing $0.05 \%(\mathrm{v} / \mathrm{v})$ Tween 20 (TTBS) and $5 \%(\mathrm{w} / \mathrm{v})$ skimmed milk (Marvel). The nitrocellulose sheets were washed four times in TTBS. Strips of approximately $3 \mathrm{~mm}$ were cut from the sheets and these were incubated overnight at room temperature with individual antisera diluted 200-fold in TTBS containing $10 \%(\mathrm{v} / \mathrm{v})$ normal goat serum (NGS). Strips were washed again in TTBS and incubation continued for $1 \mathrm{~h}$ with swine anti-rabbit IgG conjugated to alkaline phosphatase (Dako, 1:3000 dilution in TTBS containing 5\% skimmed milk). Following a further wash the antigen-antibody complexes were visualized by conventional methods using 5-bromo-4-chloro-3-indolyl phosphate and nitroblue tetrazolium (Sigma). The reaction was stopped by washing the strips in distilled water.

Immunogold-labelling. Frozen stocks of chlamydial EB were thawed, pelleted by centrifugation $(12000 \mathrm{~g}$ for $2 \mathrm{~min}$ ) in a microcentrifuge, washed once, then resuspended in PBS (Dulbecco A). The washed EB were mixed with test antisera at a final dilution of $1: 10$ in PBS and incubated for $1 \mathrm{~h}$ at $37^{\circ} \mathrm{C}$. After washing twice in PBS, the EB were resuspended in a solution of gold conjugate $(15 \mathrm{~nm}$ colloidal gold coupled to protein $\mathrm{G}$, Super EM grade, Biocell Research Laboratories, UK; $1: 10$ dilution in PBS) and incubated for a further $1 \mathrm{~h}$ at $37^{\circ} \mathrm{C}$. The goldlabelled EB were washed once in PBS, then in water and mounted on polylysine-treated, carbon-coated, nickel/Formvar grids. The chlamydiae were examined in an Hitachi H7000 TEM either without negative stain or after brief $(15 \mathrm{~s})$ counterstaining with $0.25 \%(\mathrm{w} / \mathrm{v})$ uranyl acetate.

Microimmunofluorescence. The serological specificity of the peptide antisera was kindly determined against the 15 internationally recognized serovars of $C$. trachomatis and against $C$. psittaci and $C$. pneumoniae by $\mathrm{Dr}$ John Treharne (Institute of Ophthalmology, London University, UK) by micro IF using the methods of Darougar \& Treharne (1981).

Epitope mapping. Solid-phase peptides for epitope mapping were synthesized according to a published method (Geysen et al., 1984) using a commercial kit (Cambridge Research Biochemicals, Cambridge, UK). Synthesis was performed according to the manufacturer's instructions and as previously described (Conlan et al., 1988).

\section{RESULTS}

Synthetic peptides

The synthetic peptides used in the present study are shown in Table 1 . The positions of predicted $\beta$-turns are underlined. The locations of these peptide sequences on MOMP are indicated.

\section{Production of anti-peptide antibodies}

All of the peptide-KLH conjugates, except peptide 8, generated high-titre antibodies reactive with the free peptide on ELISA (Table 2). Five of these high-titre anti-peptide sera were monospecific for the homologous peptide only. Peptide 1 produced antibodies which crossreacted with peptide 2 , with which it shared the sequence ${ }^{75}$ APSTL ${ }^{79}$. Surprisingly, antibody to peptide 1 also reacted with peptide 9 , with which it shared no primary sequence. This cross- 
Table 1. Synthetic peptide homologues of C. trachomatis serovar B MOMP

Computer-predicted epitopic regions of $C$. trachomatis MOMP. Underlined regions have an overall $\beta$-turn potential of $P>1.5 \times 10^{-4}$. Bold type, hydrophilic domains, italics, non-natural sequence added for coupling and detection. Residues are numbered from the $\mathrm{N}$-terminus and are indicated by the single-letter code: A, alanine; C, cysteine; D, aspartic acid; E, glutamic acid; F, phenylalanine; G, glycine; I, isoleucine; $L$, leucine; $M$, methionine; $N$, asparagine; $P$, proline; $Q$, glutamine; $R$, arginine; $\mathrm{S}$, serine; T, threonine; V, valine; $\mathrm{Y}$, tyrosine. VS, variable segment; $\mathrm{C}$, constant region.

\begin{tabular}{|c|c|c|}
\hline Peptide & Sequence & Location \\
\hline 1 & $Y^{69}{ }^{1 T G N A A A P S T L}{ }^{79} C$ & VS1 \\
\hline 2 & $Y^{7 \text { APSTLTARENP }}{ }^{85} C$ & VS1 \\
\hline 3 & ${ }^{116}$ TLGASSGYLKGN ${ }^{127} \mathrm{C}$ & $\mathrm{C}$ \\
\hline 4 & ${ }^{135}$ GLFGNNENQTKV ${ }^{146} C$ & VS2 \\
\hline 5 & ${ }^{144}$ TKVSNGAFVPNM $^{155} \mathrm{C}$ & VS2 \\
\hline 6 & ${ }^{214}$ TINKPKGYVGKE $225 \mathrm{C}$ & $\mathrm{C}$ \\
\hline 7 & ${ }^{275}$ SFDADTIRIAQP ${ }^{286} C$ & $\mathrm{C}$ \\
\hline 8 & ${ }^{288}$ SAETIFDVTTL ${ }^{298} C$ & VS4 \\
\hline 9 & $Y^{298}$ LNPTIAGAGDV $^{308} C$ & VS4 \\
\hline
\end{tabular}

Table 2. Reactivity of antisera (ELISA titre) with peptide antigens and whole chlamydiae

All assays were performed at least in triplicate. All pre-bleed sera gave titres of 18 . Titres $<54$ not shown. (VS), variable segment; (C), constant region.

\begin{tabular}{|c|c|c|c|c|c|c|c|c|c|c|c|}
\hline \multirow[b]{2}{*}{ Antiserum } & \multirow[b]{2}{*}{ Peptide } & \multicolumn{10}{|c|}{ Antigen (region): } \\
\hline & & $\begin{array}{c}1 \\
\text { (VS1) }\end{array}$ & $\stackrel{2}{2}$ & $\stackrel{3}{(\mathrm{C})}$ & $\begin{array}{c}4 \\
\text { (VS2) }\end{array}$ & $\stackrel{5}{\text { (VS2) }}$ & $\stackrel{6}{(\mathrm{C})}$ & $\begin{array}{c}7 \\
(\mathrm{C})\end{array}$ & $\begin{array}{c}8 \\
\text { (VS4) }\end{array}$ & $\begin{array}{c}9 \\
\text { (VS4) }\end{array}$ & $\begin{array}{c}\text { Whole } \\
\text { chlamydiae }\end{array}$ \\
\hline \multicolumn{12}{|l|}{ Anti-peptide } \\
\hline 1 & & 118000 & 39366 & & & & & & & 13192 & \\
\hline 2 & & & 118000 & & & & & 486 & & 162 & \\
\hline 3 & & & & 118000 & 486 & & 39366 & 486 & & 162 & \\
\hline 4 & & & & & 118000 & & 162 & & 486 & & 162 \\
\hline 5 & & & & 486 & 162 & 39366 & 486 & 486 & 486 & 486 & 162 \\
\hline 6 & & & & 13122 & 162 & & 118000 & & & & 486 \\
\hline 7 & & & & 486 & 486 & & 486 & 118000 & 486 & 162 & \\
\hline 8 & & & & 486 & 486 & & 486 & 162 & 486 & & 4374 \\
\hline 9 & & & & & & & 162 & & & 39366 & 13122 \\
\hline Anti-chlamydia & & & 162 & & 162 & & 162 & & 162 & 162 & 13122 \\
\hline
\end{tabular}

reactivity was one-way, as antibody raised against peptides 2 and 9 did not react with peptide 1 . Antibody to peptide 3 reacted with peptide 6 and vice versa (see Discussion). Antibody raised against peptide 8 reacted poorly with the homologous peptide antigen by ELISA but showed good reactivity with chlamydiae. Antibodies raised against whole EB reacted only poorly with all of the solid-phase peptides.

Reactivity of anti-peptide antibodies with whole EB was initially determined by ELISA. Antibodies to peptides 8 and 9 showed high-titre reactivity with whole EB on ELISA. By contrast, antiserum to peptide 5 , which was strongly reactive with either denatured MOMP (see below) or with the homologous peptide, reacted at only low titre in ELISA with chlamydial EB. Antisera to peptides 4 and 6 also reacted only poorly with whole organisms on ELISA. Antipeptide sera 1,2,3 and 7, which reacted strongly by ELISA with the homologous peptide, failed to react with the analogous sequence on native EB.

\section{Reactivity of anti-peptide antibodies with MOMP}

The specificity of the anti-peptide sera for chlamydial antigens was determined by Western blotting. Antibodies raised against peptides 5, 8 and 9 reacted strongly with denatured serovar $B$ MOMP on Western blotting (Fig. 1). Antibody to peptide 6 also reacted, but less strongly, whilst antibody to peptide 1 showed only weak reactivity. Thus the high-titre antibody generated by 


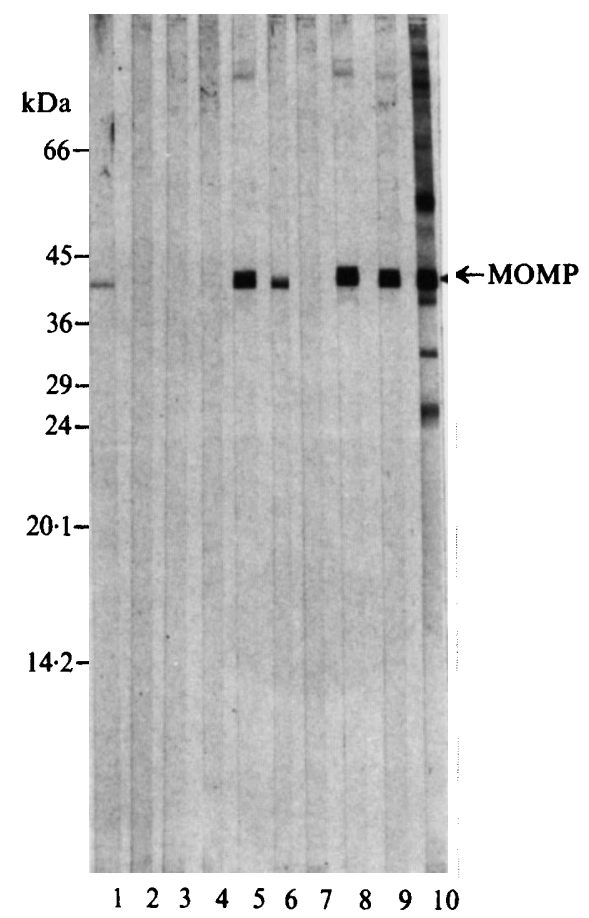

Fig. 1. Western blots of SDS-PAGE separated whole chlamydiae with antisera raised against peptides. Lanes 1-9, antisera raised against peptides $1-9$ respectively; lane 10 , antiserum to whole $C$. trachomatis serovar B. The positions of molecular mass markers are indicated.

peptide 1 against free peptide 9 did not identify this sequence in the context of whole, denatured MOMP. Similarly anti-peptide 3 antibody, which cross-reacted with free peptide 6 , did not recognize this sequence in denatured MOMP.

\section{Surface accessibility of MOMP epitopes}

The surface accessibility of MOMP epitopes on intact chlamydiae was determined by immunogold-labelling in conjunction with TEM. Two morphologically distinct forms of chlamydial particles were visible in the preparations used (Fig. 2). One form was approximately $0.3 \mu \mathrm{m}$ in diameter with an electron-dense nuclear region in the absence of negative stain. These were EB. The second form was relatively electron-lucent, with a diameter from 0.3 to $0.6 \mu \mathrm{m}$. We believe, from observations of similar preparations examined in thin section, that these were intermediate bodies (IB) in the later stages of maturation. The ratio of electron dense :lucent particles was approximately $3: 1$. Antisera to peptides $1,5,8$ and 9 showed significant reactivity with both EB and IB (Table 3), but reactivity of antibodies to peptides 1, 5 and 8 was significantly greater with IB than with EB. The extent to which this was due to differences in surface area is difficult to ascertain because of the variability in size of the IB. However, surface area cannot account for the most significant differences, as antibody to peptide 9 reacted equally well with both EB and IB, whilst antibody raised against peptides 4 and 6 reacted only with IB. In all cases there was wide variation in the labelling of individual organisms (Table 3 ).

\section{Serological specificity of anti-peptide antibodies}

The reactivity of anti-peptide antisera with acetone-fixed chlamydiae was determined by microimmunofluorescence (micro IF). The results are presented in Table 4, which also summarizes antiserum reactivity determined by Western blot, ELISA and immunogold-TEM. Four of the anti-peptide sera $(2,3,4$ and 7$)$ were negative in the relatively insensitive micro IF 
(a)

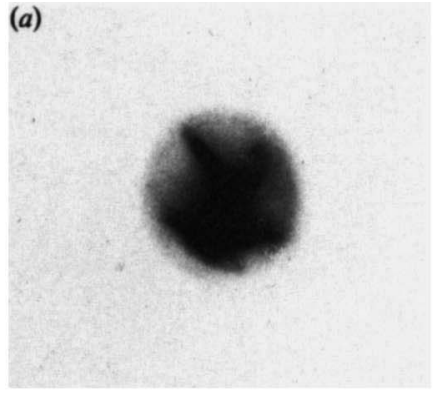

(d)

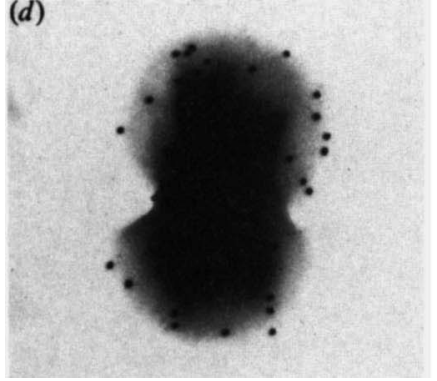

(b)

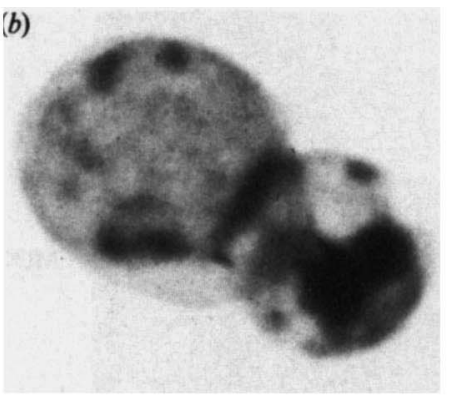

(e)

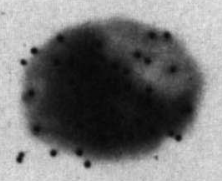

(c)

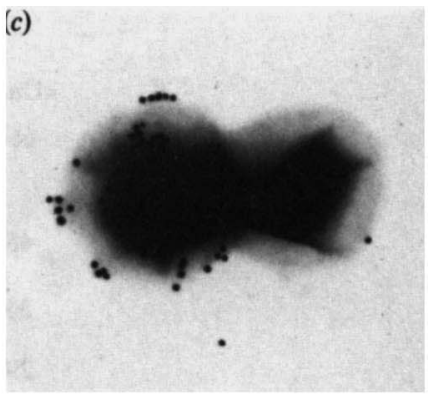

$(f)$

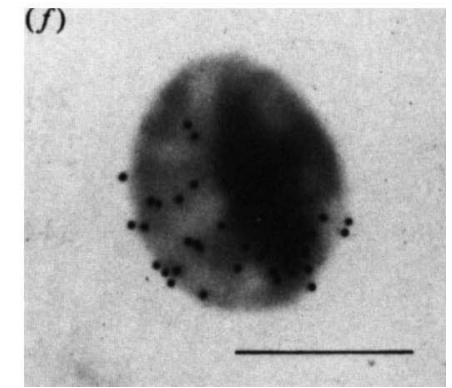

Fig. 2. Immunogold labelling of variable $C$. trachomatis. (a) EB labelled with pre-bleed serum (negative control); $(b)$ IB of different size labelled with pre-bleed serum; $(c)$ EB showing different labelling intensities with antiserum to whole chlamydiae; $(d)$ EB labelled with peptide 9 antiserum; (e) small IB labelled with peptide 9 antiserum; $(f)$ medium-sized IB labelled with peptide 9 antiserum. Bar, $0 \cdot 3 \mu \mathrm{m}$.

\section{Table 3. Labelling of intact chlamydiae by peptide antisera by immunogold-TEM}

Counts were performed on at least 30 organisms of each developmental form and the results analysed by a two-sample $t$ test. Pre-bleed antiserum against whole chlamydiae was taken as the negative control for all comparisons. Essentially similar results were obtained in two separate experiments.

\begin{tabular}{|c|c|c|c|c|c|}
\hline \multirow[b]{3}{*}{ Antiserum } & \multicolumn{4}{|c|}{ Mean (range) particles per organism } & \multirow{3}{*}{$\begin{array}{c}\text { Mean labelling } \\
\text { IB : EB }\end{array}$} \\
\hline & \multicolumn{2}{|c|}{ EB } & \multicolumn{2}{|c|}{ IB } & \\
\hline & Pre-bleed & Test-bleed & Pre-bleed & Test-bleed & \\
\hline \multicolumn{6}{|l|}{ Anti-peptide } \\
\hline 1 & ND & $1 \cdot 37^{*}(0-4)$ & ND & $8 \cdot 33 *(0-59)$ & $6 \cdot 1^{*}: 1$ \\
\hline 2 & ND & $1 \cdot 10(0-2)$ & ND & $1 \cdot 36(0-10)$ & \\
\hline 3 & $0 \cdot 76(0-5)$ & $0.19(0-2)$ & $0.94(0-4)$ & $0.80(0-10)$ & \\
\hline 4 & $0.65(0-8)$ & $1 \cdot 31 \quad(0-7)$ & $0.79(0-4)$ & $3 \cdot 42 *(0-20)$ & \\
\hline 5 & ND & $2 \cdot 52 *(0-13)$ & ND & $16.94 *(0-44)$ & $6 \cdot 7^{*}: 1$ \\
\hline 6 & ND & $0.46(0-4)$ & ND & $3 \cdot 85^{*}(0-24)$ & \\
\hline 7 & ND & $0 \cdot 10(0-2)$ & ND & $1.69(0-5)$ & \\
\hline 8 & $0 \cdot 56(0-5)$ & $8 \cdot 64 *(0-52)$ & $0.95(0-5)$ & $66 \cdot 13^{*}(5-213)$ & $7 \cdot 6^{*}: 1$ \\
\hline 9 & $0.08(0-1)$ & $30 \cdot 36^{*}(0-113)$ & $1.23(0-8)$ & $37 \cdot 0^{*} \quad(0-90)$ & \\
\hline Anti-chlamydia & $0.34(0-4)$ & $12 \cdot 6^{*}(0-58)$ & $0.82(0-5)$ & $68 \cdot 8^{*}(3-209)$ & $5 \cdot 5^{*}: 1$ \\
\hline
\end{tabular}

assay. Antibody to peptide 5 showed weak $C$. trachomatis serovar B type specificity, whilst antipeptide sera 1, 6 and 8 showed weak specificity for serovar L1. Antibody produced against peptide 9 showed strong reactivity with the B-subspecies serovars of $C$.trachomatis $(\mathrm{B}, \mathrm{D}, \mathrm{E}, \mathrm{F}$, $G, L 1, L 2)$ and was negative against the $C$ subspecies serovars. Antiserum raised against whole serovar B chlamydiae was species-specific, reacting with all $C$. trachomatis serovars but not with C. psittaci or C. pneumoniae. 


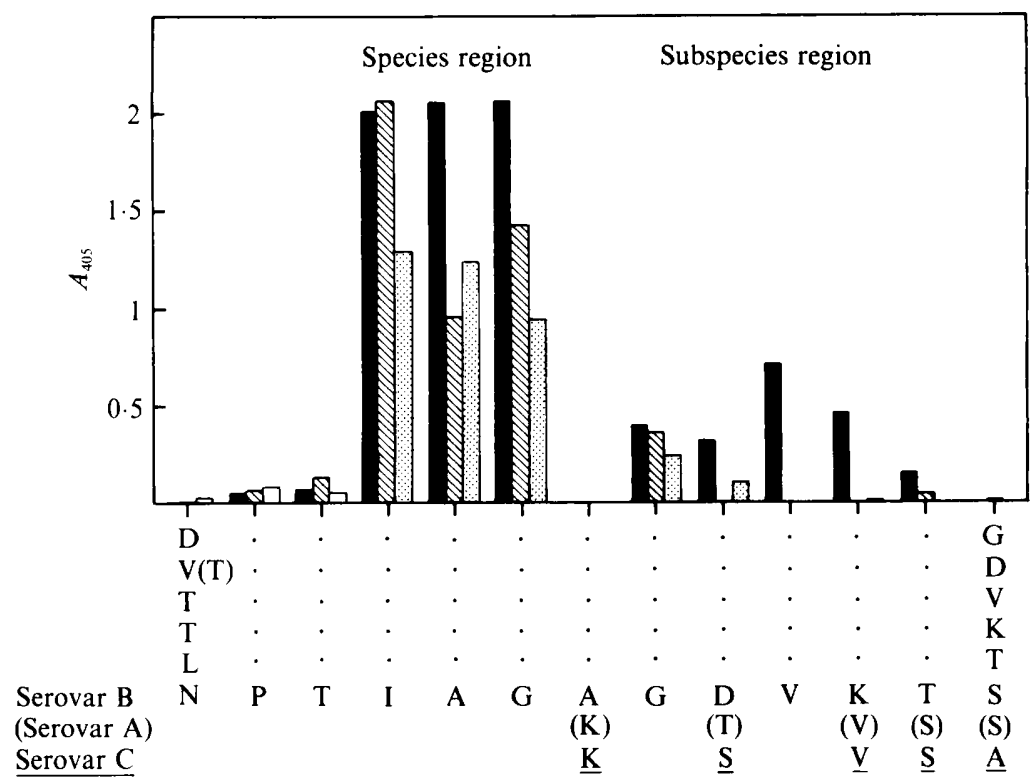

Fig. 3. ELISA reactivity of peptide 9 antiserum with synthetic, overlapping solid-phase hexapeptide homologues spanning the amino acid sequence DVTTLNPTIAGAGDVKTS in VS4. Normal type, serovar B sequence; type in parentheses, changes in serovar A sequence as compared with serovar B; underlined type, changes in serovar C sequence as compared with serovar B (based on data from Yuan et al. (1989). $\mathbf{\square}$, Reactivity with serovar A peptides; $\mathbf{\square}$, reactivity with serovar B peptides; $\mathbf{E}$, reactivity with serovar $\mathrm{C}$ peptides.

Table 4. Serological reactivity of peptide antisera determined by micro IF, Western blot, ELISA and immunogold-TEM

\begin{tabular}{|c|c|c|c|c|c|c|}
\hline \multirow[b]{3}{*}{ Antiserum } & \multicolumn{5}{|c|}{ Reactivity with chlamydiae } & \multirow{3}{*}{$\begin{array}{c}\text { Reactivity } \\
\text { with free } \\
\text { peptide }\end{array}$} \\
\hline & \multirow[b]{2}{*}{ Micro IF* } & \multirow{2}{*}{$\begin{array}{c}\text { Western } \\
\text { blot }\end{array}$} & \multirow[b]{2}{*}{ ELISA } & \multicolumn{2}{|c|}{ Immunogold } & \\
\hline & & & & $\mathrm{EB}$ & $\mathrm{IB}_{\mathrm{IB}}$ & \\
\hline \multicolumn{7}{|l|}{ Anti-peptide } \\
\hline 1 & L1-specific (16) & + & - & + & + & + \\
\hline 2 & Negative & - & - & - & - & + \\
\hline 3 & Negative & - & - & - & - & + \\
\hline 4 & Negative & - & - & - & + & + \\
\hline 5 & B-specific (16) & + & + & + & + & + \\
\hline 6 & L1-specific (16) & + & + & - & + & + \\
\hline 7 & Negative & - & - & - & - & + \\
\hline 8 & Ll-specific & + & + & + & + & - \\
\hline 9 & $\begin{array}{l}\text { B-subspecies specific; } \\
\text { B }(256) ; \text { D }(256) ; \\
\text { E }(256) ; \text { F }(64) ; \\
\text { G }(64) ; \text { K }(16) ; \\
\text { L1 (64); L2 (128); } \\
\text { A, C, H, I, J, } \\
\text { L3 (negative) }\end{array}$ & + & + & + & + & + \\
\hline Anti-chlamydia & Species specific & + & + & + & + & - \\
\hline
\end{tabular}

* Figures in parentheses indicate titre values.

\section{Epitope mapping}

The subspecies reactivity of antibodies to peptide 9 , as shown by micro IF and their ability to surface-label chlamydiae by immunogold-TEM, was unexpected. The critical binding sites of these antibodies were therefore investigated using the Geysen (1984) method of epitope 
mapping as we have previously described (Conlan et al., 1988, 1989). The results are presented in Fig. 3. The antiserum to peptide 9 contained antibodies reactive with the species-specific peptides TLNPTI, LNPTIA and NPTIAG and also antibodies reactive in a subspecies-specific manner with peptides IAGAGD, AGAGDV, GAGDVK and AGDVKT (serovar B) but not with the analogous peptides of MOMP from serovars $A$ or $C$.

\section{DISCUSSION}

The failure of whole-organism vaccines against trachoma and the occurrence of disease of enhanced severity in some vaccinated subjects (reviewed in Schachter \& Dawson, 1978) has focussed attention on the use of chlamydial surface antigens as sub-unit vaccine components. MOMP is a favoured vaccine candidate because it comprises up to $60 \%$ of the protein at the surface of the infectious EB (Caldwell et al., 1981) and antibodies to it are capable of neutralizing chlamydial infection (Lucero \& Kuo, 1985: Zhang et al., 1987). Neutralization both in vivo and in vitro depends on the immunoaccessibility of the target MOMP epitopes (Kuo \& Chi, 1987; Zhang et al., 1987). Thus antibodies to the immunodominant, surface-exposed, type and subspecies epitopes neutralize chlamydial infections whereas antibody to the less accessible species epitope does not. These epitopes are located in variable regions of MOMP (Baehr et al., 1988; Conlan et al., 1988; Stephens et al., 1987), forming surface-exposed loops accessible to proteolytic digestion (Baehr et al., 1988; Su et al., 1988) and accounting for some $20 \%$ of the protein sequence. Two major questions arise. Firstly, are there any B-cell epitopes present on conserved regions of the protein? Such regions, although not immunodominant, might be associated with conserved, important biological functions, e.g. the MOMP porin function, regulation of the developmental cycle (Bavoil et al., 1984; Ward, 1988) or interaction with the host cell (Ward, 1986). Secondly, is it possible using short-chain peptides as vaccines to target the antibody response to selected epitopes on the chlamydial surface despite the heavily $\mathrm{S}-\mathrm{S}$ interlinked structure of the outer envelope of infectious EB?

As the basis for our studies we selected the primary sequence of C. trachomatis serovar B MOMP, as these organisms are one of the major causes of blinding trachoma. The program of Krchnak et al. (1987), which we used for epitope prediction, calculates turn probabilities and hydrophilicity using the conventional algorithms of Chou \& Fasman (1978) and Hopp \& Woods (1981). Using this program $>98 \%$ correlation was observed between peptides with a $\beta$-turn potential $(P)>1.5 \times 10^{-4}$ and the ability of antibody against the corresponding synthetic peptide homologue to react back to the native protein (Krchnak et al., 1987).

Six of the nine predicted epitopes selected for synthesis fell within VS1, 2 or 4 whilst the remaining peptides were from regions of conserved sequence. Only peptide 8 (SAETIFDVTTLC), corresponding to the known subspecies-specific epitope on VS4 (Stephens et al., 1988; Conlan et al., 1988), failed to generate antibody reactive at high titre with the immunizing peptide on ELISA. Nevertheless peptide 8 was highly immunogenic, eliciting antibody reactive with whole chlamydiae both on ELISA and immunogold-TEM. The remaining peptides, in general, produced high titre antibodies which were mono-specific for the homologous peptide on ELISA. The cross-reactivity of antiserum to peptide 1 with peptide 2 was probably associated with the common sequence APSTL, a region with a high turn probability which might form a loop. Less easy to explain is the high cross-reactivity of this antiserum with the apparently unrelated peptide 9 (YLNPTIAGAGDVC). Similar crossreactivity was not observed against denatured or native MOMP. The cross-reactivity observed between antibodies to peptide TLGASSGYLKGNC and peptide TINKPKGYVGKEC and vice versa probably reflects the high degree of functional homology (residues underlined) shown by these two peptides.

In many cases (peptides 2, 3, 4 and 7) the synthetic peptides seem to have inadequately represented the conformation of the same sequences within native MOMP as antisera to them reacted better on ELISA with the immunizing peptide than with whole chlamydiae. Conversely, this could also explain why antibodies produced by immunization with whole organisms showed only weak reactivity with bound peptide antigens. This was anticipated given the 
conformational flexibility of short peptides, the likely structural contraints within proteins and the fact that antibody to most proteins is probably against discontinuous, rather than continuous epitopes. Similar limitations of anti-peptide sera have been observed in other systems (Shinnick et al., 1983).

Antibodies to peptides 1, 2 (VS1), 3 and 7 (constant regions) failed to react significantly with whole chlamydiae on ELISA, although anti-peptide 1 serum reacted moderately with intact organisms by immunogold-TEM. Antisera to peptides 4, 5 (VS2), 6 (constant region), 8 and 9 (VS4) reacted with whole chlamydiae on ELISA and all except peptide 4 and 6 antibodies recognized surface exposed eptiopes on EB. Peptide 8 (VS4) encompasses the known surfaceexposed B subspecies-specific epitope, IFDV (Conlan et al., 1988). Peptide 9, also in VS4, generated antibody strongly reactive with the chlamydial surface by immunogold-TEM. This peptide encompasses the species-specific epitope LNPTIAG (Stephens et al., 1988; Conlan et al., 1988; Baehr et al., 1988), which is not exposed at the surface of EB. Thus, the antibodies reacting with intact chlamydiae must be directed against the sequence AGDV at the C-terminus of peptide 9. This sequence is conserved in B-complex but not in C-complex serovars (Yuan et al., 1989). Hence, reactivity with this domain could explain the subspecies-specificity of peptide 9 antiserum on micro IF. Baehr et al. (1988) have reported a subspecies-specific epitope downstream of LNPTIAG. This hypothesis was confirmed by solid-phase peptide mapping across peptide 9. This demonstrated that peptide 9 antiserum reacted with species-specific peptides and also with B-complex subspecies-specific peptides but not with analogous Ccomplex peptides.

This work demonstrates the feasibility, using synthetic peptide antigens, of targeting the antibody response to immunoaccessible, potentially neutralizing epitopes on MOMP. Of further interest was the finding that chlamydiae vary greatly, both individually, and in relationship to the developmental cycle, in the surface exposure of selected epitopes. This is in contrast to a recent report by Collett et al. (1989), who achieved uniform, high-density labelling of all developmental forms of chlamydiae. There are several possible explanations for this. Collett $e t$ al. (1989) coated the chlamydiae directly to grids prior to labelling and this might alter their surface conformation. On-grid labelling by these workers also allowed a more gentle washing procedure to be employed; the vigorous washing associated with the suspension labelling employed here is likely to have precluded detection of all but high-avidity antibody binding. Similar marked variation in immunogold surface labelling has been shown for Neisseria using methods identical to those employed in the present study (Paques et al., 1989). Unfortunately it was the highly infectious EB which showed minimal surface exposure of MOMP epitopes. This presumably reflects the highly cross-linked structure of the EB outer envelope, necessary for structural stability in the absence of peptidoglycan. In this respect it is particularly interesting that antibody to peptide 9 bound well to both EB and IB; this domain warrants more detailed investigation. Our results confirm the immunodominance and surface-exposure of the VS1, VS2 and VS4 regions of MOMP in situ and suggest that the question of both individual and developmental variation in the surface exposure of MOMP epitopes must be addressed in chlamydial vaccine design.

We thank Dr John Treharne for performing the micro IF assays and Chris Inman for his expert help with electron microscopy. This work was funded by grants from the Edna McConnell Clark Foundation, New York.

\section{REFERENCES}

Baehr, W., Zhang, Y.-X., Joseph, T., SU, H., Nano, F. E., Everett, D. E. \& Caldwell, H. D. (1988). Mapping antigenic domains expressed by Chlamydia trachomatis major outer membrane protein (MOMP) genes. Proceedings of the National Academy of Sciences of the United States of America 85, 40004004.

Ba voil, P., Ohlin, A. \& Schachter, J. (1984). Role of disulfide bonding in outer membrane structure and permeability in Chlamydia trachomatis. Infection and Immunity 44, 479-485.
Caldwell, H. D. \& Perry, L. (1982). Neutralization of Chlamydia trachomatis infectivity with antibodies to the major outer membrane protein. Infection and Immunity 38, 745-754.

Caldwell, H. D., Kromhout, J. \& Schachter, J. (1981). Purification and partial characterisation of the major outer membrane protein of Chlamydia trachomatis. Infection and Immunity 31, 1161-1176.

Chou, P. Y. \& Fasman, G. D. (1978). Prediction of the secondary structure of proteins from their amino acid sequence. Advances in Enzymology 47, 45-147. 
Collett, B. A., Newhall, W. J., Jersild, V. R. A. \& JONES, R. B. (1989). Detection of surface-exposed epitopes on Chlamydia trachomatis by immune electron microscopy. Journal of General Microbiology 135, 85-94.

Conlan, J. W., Clarke, I. N. \& Ward, M. E. (1988). Epitope mapping with solid phase peptides: identification of type-, subspecies-, species-, and genusreactive antibody binding domains on the major outer membrane protein of Chlamydia trachomatis. Molecular Microbiology 2, 673-679.

Conlan, J. W., Kajbaf, M., Clarke, I. N., Chantler, S. \& WARD, M. E. (1989). The major outer membrane protein of Chlamydia trachomatis: critical binding site and conformation determine the specificity of antibody binding to viable chlamydiae. Molecular Microbiology 3, 311-318.

Darougar, S. \& Treharne, J. D. (1981). Chlamydial infections: laboratory aspects. In Recent Advances in Sexually Transmitted Diseases 2, pp. 141-150. Edited by R. W. Harris. London: Churchill Livingstone.

EllmaN, G. L. (1959). Tissue sulfhydryl groups. Archives of Biochemistry and Biophysics 82, 70-77.

Geysen, H. M., Meloen, R. H. \& Barteling, S. J. (1984). Use of peptide synthesis to probe viral antigens for epitopes to a resolution of a single amino acid. Proceedings of the National Academy of Sciences of the United States of America 81, 3998-4002.

Green, N., Alexander, H., Olson, A., AleXander, S., Shinnick, T., Sutcliffe, J. \& Lehner, R. A. (1982). Immunogenic structure of the influenza virus haemagglutinin. Cell 28, 477-478.

Hatch, T. P., Allan, I. \& Pearce, J. H. (1984). Structural and polypeptide differences between envelopes of infective and reproductive life cycle forms of Chlamydia spp. Journal of Bacteriology 157, 13-20.

HoPP, T.P.\&Woods, K. R. (1981). Prediction of protein antigenic determinants from amino acid sequences. Proceedings of the National Academy of Sciences of the United States of America 78, 3824-3828.

KaISER, E., COlescott, R. L., Bossinger, C. D. \& Cook, P. I. (1970). Color test for detection of free terminal amino acid groups in the solid-phase synthesis of peptides. Analytical Biochemistry 34, 595-598.

Kaiser, E., Bossinger, C. D., Colescott, R. L. \& OLSEN, D. B. (1980). Color test for terminal prolyl residues in the solid-phase synthesis of peptides. Analytica chimica acta 118, 149-151.

KYHSE-ANDERSEN, J. (1984). Electroblotting of multiple gels: a simple apparatus without buffer tank for rapid transfer of proteins from polyacrylamide to nitrocellulose. Journal of Biochemistry and Biophysical Methods 10, 203-209.

Krchnak, V., Mach, O. \& Maly, A. (1987). Computer prediction of potential immunogenic determinants from protein amino acid sequence. Analytical Biochemistry 165, 200-207.

Kuo, C. C. \& CHI, E. Y. (1987). Ultrastructural study of Chlamydia trachomatis surface antigens by immunogold staining with monoclonal antibodies. Infection and Immunity 55, 1324-1328.

LAEMMLI, U. K. (1970). Cleavage of structural proteins during the assembly of bacteriophage T4. Nature, London 227, 680-685.
LUCERo, M. E. \& Kuo, C. C. (1985). Neutralization of Chlamydia trachomatis cell culture infection by serovar-specific monoclonal antibodies. Infection and Immunity 50, 595-597.

Paques, M., Teppema, J. S., Beuvery, E. C., Abdillahi, H., Poolman, J. T. \& VerkleiJ, A. J. (1989). Accessibility of gonococcal and meningococcal surface antigens : immunogold labelling for quantitative electron microscopy. Infection and Immunity 57, 582-589.

Picketr, M. A., Ward, M. E. \& Clarke, I. N. (1987). Complete nucleotide sequence of the major outer membrane protein gene from Chlamydia trachomatis serovar L1. FEMS Microbiology Letters 42, 185-190.

Pickett, M. A., Everson, J. S. \& Clarke, I. N. (1988). Chlamydia psittaci ewe abortion agent: complete nucleotide sequence of the major outer membrane proteingene. FEMS Microbiology Letters 55, 229-234.

Robertson, J. N., WARD, M. E., ConWAy, D. \& CAUL, E. O. (1987). Chlamydial and gonococcal antibodies in sera of infertile women with tubal obstruction. Journal of Clinical Pathology 40, 377-383.

Salari, S. H. \& Ward, M. E. (1981). Polypeptide composition of Chlamydia trachomatis. Journal of General Microbiology 123, 197-207.

SCHACHTER, J. \& DAwson, C. (1978). Chlamydial Infections. Littleton, Mass; PSG Publishing.

Shinnick, T. M., Sutcliffe, J. G., Green, N. \& LEHNER, R. A. (1983). Synthetic peptide immunogens as vaccines. Annual Review of Microbiology 37, 425-446.

StePhens, R. S., SANChez-Pescador, R., Wagar, E. A., INUOYE, C. \& URDEA, M. S. (1987). Diversity of Chlamydia trachomatis major outer membrane protein genes. Journal of Bacteriology 169, 3879-3885.

Stephens, R. S., Wagar, E. A. \& Schoolnik, G. K. (1988). High resolution mapping of serovar-specific and common antigenic determinants of the major outer membrane protein of Chlamydia trachomatis. Journal of Experimental Medicine 167, 817-831.

Su, H., Zhang, Y.-X., Barrera, O., Watkins, N. G. \& Caldwell, H. D. (1988). Differential effect of trypsin on the infectivity of Chlamydia trachomatis: loss of infectivity requires cleavage of MOMP variable domains II and IV. Infection and Immunity 56, 2094-2100.

WARD, M. E. (1986). Outstanding problems in chlamydial cell biology. In Chlamydial Infections: Proceedings of the Sixth International Symposium on Human Chlamydial Infections, pp. 3-14. Edited by D. Oriel, G. Ridgeway, J. Schachter, D. Taylor-Robinson \& M. Ward. Cambridge: Cambridge University Press. WARD, M. E. (1988). The chlamydial developmental cycle. In Microbiology of Chlamydia, pp. 71-91. Edited by R. Barron. Boca Raton: CRC Press.

Yuan, Y., Zhang, Y.-X., Watkins, N. G. \& CaldWELL, H. D. (1989). Nucleotide and deduced amino acid sequences for the four variable domains of the major outer membrane proteins of the 15 Chlamydia trachomatis serovars. Infection and Immunity 57, 1040-1049.

Zhang, Y.-X., Stewart, S., Joseph, T., TAylor, H. R. \& Caldwell, H. D. (1987). Protective monoclonal antibodies recognise epitopes located on the major outer membrane protein of Chlamydia trachomatis. Journal of Immunology 138, 575-581. 